\title{
评述
}

\section{基于多组学的黄芩活性成分生物合成及合成 生物学研究进展}

高再再 ${ }^{1}$, 徐志超 ${ }^{1,2}$, 浦香东 ${ }^{1}$, 宋经元 ${ }^{1,2,3^{*}}$

1. 中国医学科学院\&北京协和医学院药用植物研究所, 国家中医药管理局中药资源保护重点研究室, 北京 100193 ;

2. 中药资源教育部工程研究中心, 北京 100193 ;

3. 中国医学科学院\&北京协和医学院药用植物研究所云南分所, 景洪 666100

* 联系人, E-mail: jysong@implad.ac.cn

收稿日期：2020-06-11; 接受日期：2020-07-31; 网络版发表日期：2020-09-21

国家重点研发计划(批准号: 2019YFC1711100)和中国医学科学院本草基因组协同创新团队项目(批准号: 2016-I2M-3-016)资助

摘要黄芩作为大宗常用中药, 具有清热燥湿、泻火解毒等功效, 在近期暴发的新型冠状病毒肺炎(coronavirus disease 2019, COVID-19)的治疗中作用显著. 黄芩主要活性成分为一类特殊的黄酮类化合物, 在黄芩属之外的物 种中军见, 其生物合成途径及体外合成生物学研究是国际关注热点. 中药黄芩基原植物存在野生资源短缺、人工 栽培种质退化、质量不稳定等问题. 多组学技术的应用和发展, 可从分子层面揭示药用植物遗传信息及活性成分 合成和调控机制, 推动中药科学研究和实践应用. 本文系统总结了黄芩基因组、转录组、蛋白质组、代谢组等多 组学的研究进展, 归纳了黄芩活性成分生物合成途径关键酶的鉴定、转录因子的调控研究及黄芩苷类化合物的 微生物体外生产, 并提出未来函待解决的科学问题, 如基因组辅助育种、黄芩生长发育及活性成分合成及调控机 制、活性成分体外合成产率优化等, 为有效解决黄芩优良种质资源的培育及质量问题奠定了基础.

关键词 黄芩, 黄酮类化合物, 生物合成, 合成生物学

唇形科黄芩属植物黄芩(Scutellaria baicalensis Georgi), 以根入药，具有清热燥湿、泻火解毒、凉血 止血、除热安胎的功效，常用于治疗湿热㾂满、泻 痢、黄疸、肺热咳嗽、痛肿疮毒、胎动不安等病症 ${ }^{[1]}$. 新型冠状病毒肺炎(coronavirus disease 2019, COVID19)正肆虐全球，中医药在新冠诊治方面发挥积极作 用，清热解毒药——黄芩受到关注. 国家中医药管理 局发布的《新型冠状病毒肺炎诊疗方案(试行第七 版)》，由黄芩等21味中药材组成的“清肺排毒汤”可用
于轻型、普通型及重型新冠肺炎患者的治疗。基于 《新冠诊疗方案(试行第七版)》《中医疫病名方精 选》推荐治疗新型冠状病毒肺炎恢复期的中医方剂, 通过分子对接VEGFR和FGFR 靶点, 篮选出潜在抗肺 纤维化活性成分命中率 $30 \%$ 以上的中药，其中以黄芩 最多 ${ }^{[2]}$. 最新药理研究显示, 黄芩提取物具有有效的抗 新冠病毒(syndrome coronavirus 2, SAR-CoV-2)活性, 黄芩素及其类似物可外源抑制SARS-CoV-2 3CL蛋白 酶 $^{[3]}$. 黄芩及其活性成分对SARS, H1N1等病毒均具有

引用格式: 高再冉, 徐志超, 浦香东, 等. 基于多组学的黄芩活性成分生物合成及合成生物学研究进展. 中国科学: 生命科学, 2021, 51: 151-166 Gao R R, Xu Z C, Pu X D, et al. Research progress in biosynthesis and synthetic biology of active ingredients of Scutellaria baicalensis Georgi based on multi-omics approach (in Chinese). Sci Sin Vitae, 2021, 51: 151-166, doi: 10.1360/SSV-2020-0185 
较好活性 ${ }^{[4 \sim 7]}$ ，以黄芩为主要成分的“双黄连”“清开 灵”“蓝芩口服液”等中成药临床常用于流感防治 ${ }^{[8]}$. 除 抗病毒活性外，黄芩及其主要成分还具有多种生物活 性, Chen等人 ${ }^{[9]}$ 在Blood杂志发文揭示汉黄芩苷可增强 磷脂爬行酶1(phospholipid scramblase 1, PLSCR1)转录 并促进其进入细胞核，从而诱导细胞周期阻滞和促进 细胞分化，成为治疗急性髓系白血病的潜在药物; Tsou等人 ${ }^{[10]}$ 在Journal of the American Chemical Society发文证实了黄芩素的抗菌活性; Dai等人 ${ }^{[11]}$ 在Proc Natl Acad Sci USA发文表明黄芩苷可改善饮食引起的 肥胖和肝脂肪变性; 此外, 近年来黄芩苷对乳腺 癌 ${ }^{[12]}$ 、脑缺血再灌注损伤 ${ }^{[13]}$ 、溃疡性结肠炎 ${ }^{[14]}$ 、甲 流致急性肺损伤 ${ }^{[6]}$ 的作用机制被逐步揭示.

黄芩主要活性成分为黄酮类化合物. 研究发现, 在

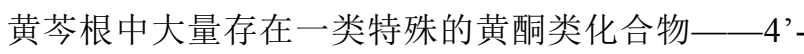
脱氧黄酮，如黄芩素、汉黄芩素及其糖苷类化合物等, 该类化合物在黄芩属之外的物种罕见, Science Advances 期刊报道了该类黄酮苷元的代谢途径及关键 酶 ${ }^{[15]}$. 随着多组学技术的发展, 药用植物基因组学、

转录组学、蛋白质组学及代谢组学等多组学研究取得 快速发展，为阐明中药防病治病的分子机制提供了指 导, 为解析药用植物生长发育机制及活性成分代谢途 径奠定了基础. 黄芩作为我国大宗常用中药材, 其基 因组和转录组已被解析，基于组学的活性成分代谢途 径及合成生物学研究也取得突破性进展. 近年来, 黄 芩综述文章多关注于化学成分、药理毒理、临床应用
等方面 ${ }^{[16 ~ 18], ~}$, 黄芩的组学研究呈现快速发展趋势，对 黄芩活性成分生物合成途径解析及合成生物学应用具 有巨大推动作用. 本文就黄芩基因组、转录组、蛋白 质组及代谢组等组学研究, 活性成分的生物合成及合 成生物学研究进展进行总结, 以期为黄芩科学研究和 实践应用提供理论支撑.

\section{1 黄芩主要活性成分及其分布特点}

类黄酮类成分为黄芩的特征性成分, 研究表明在 黄芩的地下和地上部位，黄酮类成分的种类和含量存 在明显差异, 其主要黄酮类成分的结构如图1所示 ${ }^{[19]}$. 地下根为黄芩药用部位, 存在大量 4 '-脱氧黄酮化合物, 主要包括黄芩素、去甲汉黄芩素、汉黄芩素及其糖苷 类化合物等, 该类化合物在黄芩属物种中特异存在, 黄 芩属之外仅在紫藏科木蝴蝶(Oroxylum indicum)中有 报道 ${ }^{[20]}$; 地上部分是民间常饮黄芩茶的来源之一 ${ }^{[21]}$, 地上部分黄酮类化合物主要包括芹菜素、野黄芩素、 红花素及其糖苷类化合物等. 何春年等人 ${ }^{[22]}$ 对黄芩 根、茎、叶三个部位的化学成分进行了系统比较, 发 现三个部位均主含黄酮类成分，但其主要成分显著不 同: 聚类分析显示, 茎叶部位比根部更相近; 主成分分 析显示, 茎叶与根部的区分主要为黄芩苷. 申洁 ${ }^{[19]}$ 对 黄芩不同部位 15 种主要黄酮类成分进行含量测定，其 中黄芩苷、汉黄芩苷、山姜素、黄芩素、汉黄芩素、 千层纸素A在根部含量明显高于地上部位; 异红花素-

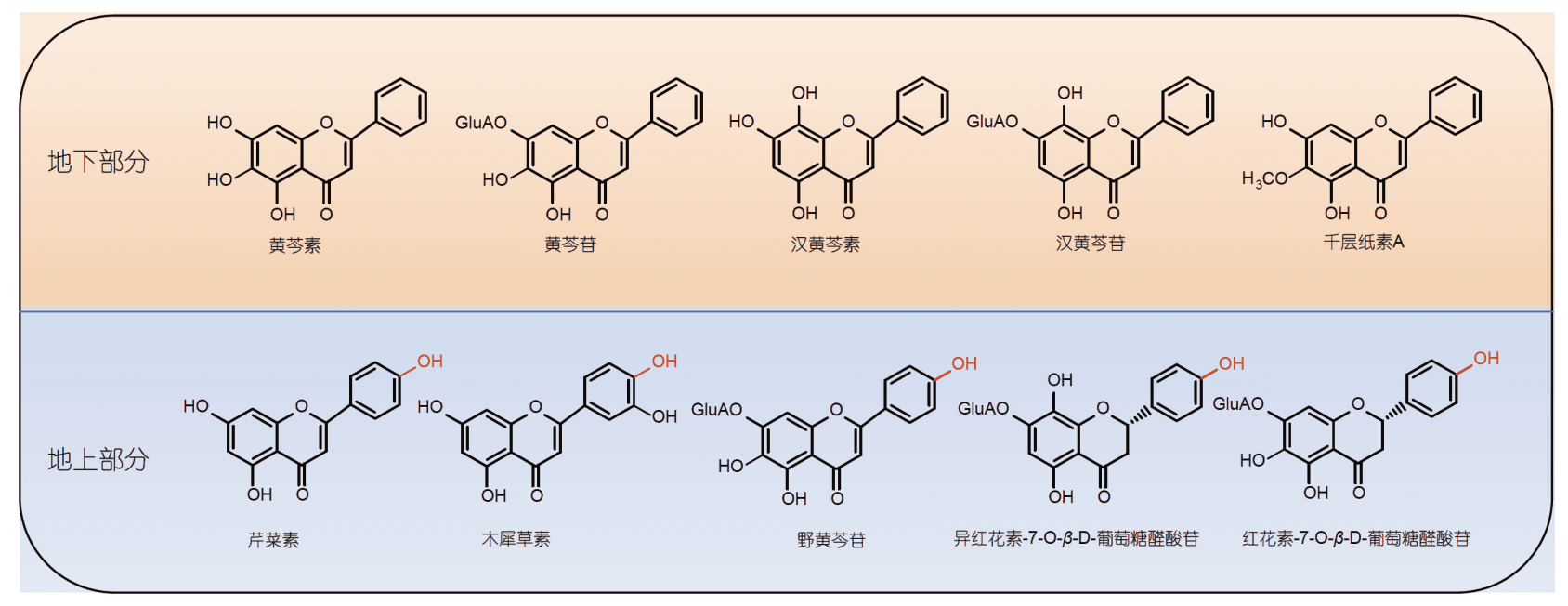

图 1 黄芩地上与地下部位主要黄酮类成分列举 ${ }^{[19]}$ (网络版彩图)

Figure 1 Main flavonoids identified in the root and aerial parts of Scutellaria baicalensis ${ }^{[19]}$ (color online) 
7-O- $\beta$-D-葡萄糖醛酸苷、红花素-7-O- $\beta$ - D- 葡萄糖醛酸 苷、野黄芩苷、大波斯菊苷、异高山黄芩素- $8-\mathrm{O}-\beta-$ $\mathrm{D}$ - 葡萄糖醛酸苷、白杨素- $7-\mathrm{O}-\beta-\mathrm{D}$ - 葡萄糖醛酸苷、 木犀草素、芹菜素在黄芩地上部位含量较高.

\section{2 黄芩基因组与转录组研究进展}

\section{1 黄芩全基因组解析及进化分析}

物种的全基因组序列包含物种起源、进化、生长 发育及其活性成分合成代谢的遗传信息. 黄芩基因组 已被解析，主要数据统计见表1. 早在2008年，Cole等 人 $^{[23]}$ 使用流式细胞技术评估黄芩基因组大小约为 $377 \mathrm{Mb}$. 黄芩正常植株为二倍体, $2 n=18$. Zhao等人 ${ }^{[24]}$ 使用流式细胞仪及 $k$-mer预测黄芩基因组大小分别为 $392 \mathrm{Mb}$ 和 $408.14 \mathrm{Mb}$; 结合二代和三代测序平台联合测 序, 组装后黄芩基因组大小为 $386.6 \mathrm{Mb}$, scaffold N50为 $1.33 \mathrm{Mb}$; 基于 $\mathrm{Hi}-\mathrm{C}$ 技术将 $98.04 \%$ 的 scaffolds挂载到 9 条染色体上，基因注释得到28930个蛋白编码基因、 1218 个miRNA、 517 个tRNA、1846个rRNA和 512 个 snRNA, GC含量为 $34.24 \%$, 基因组包含 $55.15 \%$ 的重复 序列; 比较基因组揭示黄芩与鼠尾草属植物 (Salvia spp.)分化时间为3270万年前; 基于基因组预测黄芩4'脱氧黄酮化合物合成及进化相关的基因复制、片段复 制及位点突变等，进一步验证了黄芩根中特异黄酮化
合物的生物合成途径. $\mathrm{Xu}$ 等人 ${ }^{[25]}$ 通过流式细胞技术及 $k$-mer预测黄芩基因组大小分别为(440.2 \pm 10$) \mathrm{Mb}$ 和 $441.9 \mathrm{Mb}$; 使用三代测序技术Oxford Nanopore technologies(ONT)和single molecule, real-time sequencing (SMRT) 分别对黄芩及其近缘植物半枝莲 (Scutellaria barbata)进行基因组测序, 组装后黄芩基因组大小为 $377.0 \mathrm{Mb}$ ， contig N50为 $2.1 \mathrm{Mb}$; 使用 Hi-C技术将 $99.8 \%$ 的 contigs挂载到 9 条染色体上, 注释出 33414 个 蛋白编码基因和 2833 个 ncRNA，55.2\%的黄芩基因组 序列被注释为重复序列; 基于直系同源的单拷贝基因 序列，推断黄芩与同属植物半枝莲的分化时间为 1328 万年前, 黄芩属物种与同科物种丹参(Salvia miltiorrhi$z a$ ) 的分化时间为 4101 万年前; 基于黄芩、半枝莲、丹 参、芝麻(Sesamum indicum) 和葡萄(Vitis vinifera) 的全 基因组共线性及蛋白编码基因同义替换速率 $\left(K_{\mathrm{S}}\right)$ 分析 鉴定唇形科和胡麻科共享的全基因组复制事件(whole genome duplication, WGD), 该复制事件发生在4264万 $\sim 6071$ 万年前(图2). 此外, 该研究还将黄芩与半枝莲进 行比较基因组分析, 揭示出黄芩中与黄酮类化合物合 成相关的苯丙氨酸解氨酶(phenylalanine ammonialyase, PAL)和查尔酮合成酶(chalcone synthase, CHS) 编码基因由于串联复制而扩张，半枝莲中4-香豆酰辅 酶A连接酶(4-coumarate CoA ligase, 4CL)编码基因由 于串联复制而显著扩张, 两物种中编码黄酮羟化酶

表 1 黄芩全基因组信息统计

Table 1 Characteristics of Scutellaria baicalensis genome

\begin{tabular}{ccc}
\hline & Zhao等人 ${ }^{[24]}$ & Xu等人 \\
\hline 预测基因组大小 (流式细胞技术 $/ k$-mer) & $392 \mathrm{Mb} / 408.14 \mathrm{Mb}$ & $(440.2 \pm 10) \mathrm{Mb} / 441.9 \mathrm{Mb}$ \\
染色体倍性 & $2 n=18$ & $2 n=18$ \\
杂合度 & $0.31 \%$ & $0.96 \%$ \\
组装方法 & FALCON & CANU+SMARTdenovo \\
组装基因组大小 & $386.6 \mathrm{Mb}$ & $377.0 \mathrm{Mb}$ \\
N50 & scaffold N50: 1338244 bp & contig N50: 2102880 bp \\
挂载到染色体的比例 & $98.00 \%$ & $99.80 \%$ \\
植物来源 & 上海辰山植物园 & 北京药用植物园 \\
测序平台 & Illumina+PacBio & ONT+Illumina \\
蛋白编码基因数量 & 28930 & 33414 \\
基因重复序列 & $55.15 \%$ & $55.17 \%$ \\
LTR比例 & $34.40 \%$ & $31.79 \%$ \\
数据获取 & NCBI: PRJNA484052 & NGDC: CRA001730 \\
\hline
\end{tabular}



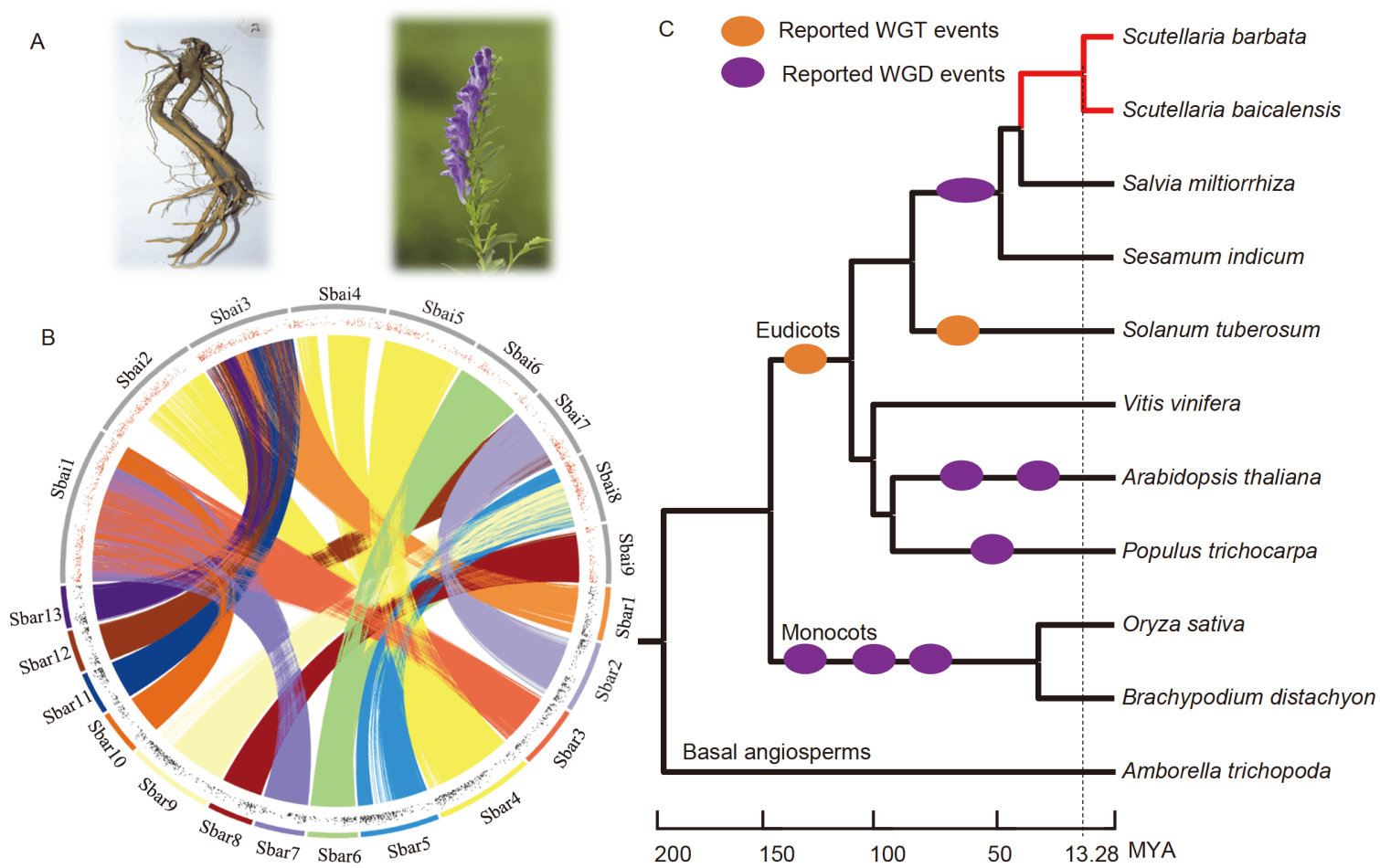

图 2 黄芩与半枝莲基因组染色体共线性及物种分化时间分析 ${ }^{[25]}$. A: 黄芩根及地上部分的形态; B: 黄芩和半枝莲基因组共线 性分析; C: 基于黄芩等基因组的物种进化及全基因组复制事件(网络版彩图)

Figure 2 Analysis of the chromosome collinearity and estimated time of species differentiation of Scutellaria baicalensis and S. barbata ${ }^{[25]}$. A: Morphology of the root and aerial part of S. baicalensis; B: collinearity detected between the genomes of S. baicalensis and S. barbata; C: phylogenetic tree featuring whole genome duplication (WGD) and whole genome triplication (WGT) events in the genomes of S. baicalensis and other angiosperm species (color online)

(flavone hydroxylase)的CYP82D基因均有串联复制.

通过比较黄芩的两个基因组测序数据(表1)发现, 两个基因组之间存在一定差异，主要包括预测基因组 大小差异 $(\sim 400 \mathrm{Mb}$ 和 $440 \mathrm{Mb})$ 、样本杂合度差异 $(0.31 \%$ 和 $0.96 \%)$ 、组装基因组大小差异 $(386.6 \mathrm{Mb}$ 和 $377.0 \mathrm{Mb}$ )、N50差异(scaffold N50 $1.34 \mathrm{Mb}$ 和contig $\mathrm{N} 502.10 \mathrm{Mb}$ )和蛋白编码基因注释数量(28930和 33414)差异. 黄芩栽培驯化时间短，遗传多样性丰富， 由于测序样本的差异、杂合度不同等原因导致已报道 基因组预测或组装的基因组大小有所不同. 此外, 测序 平台、基因组装策略、基因组注释方法等均不同，导 致基因组的组装及注释具有一定的差异. 但基因组的 组装及注释的完整性评估结果显示，两个参考基因组 的质量均较好, 足以满足目前基因挖掘、物种进化、 基因组重测序等下游分析. 目前，测序平台、生物信 息学技术等正处于飞速发展阶段，如需要进一步提升 基因组质量和注释完整性，可通过遗传图谱和物理图
谱辅助黄芩基因组进行更精细的组装，以及通过更多 的转录组或基因表达标签数据辅助基因的注释. 黄芩 参考基因组的提升对该物种遗传资源的挖掘及利用具 有重要意义.

\section{2 黄芩叶绿体基因组研究}

叶绿体基因组(chloroplast DNA, cpDNA)的遗传 信息为母系遗传，具有相对稳定的基因组结构和相对 缓慢的变异速度 ${ }^{[26]}$, 相比核基因组更易显示居群间的 地理分化，常用于系统发育研究和物种鉴定 ${ }^{[27]}$. 与大 多数植物一样, 黄芩叶绿体基因组也是由两个保守的 反向重复(inverted repeat，IR)区域(IRA和IRB)分成的 环状四分体结构. 为了研究黄芩道地性物质基础, 阐 释黄芩的分子谱系地理学，Jiang等人 ${ }^{[28]}$ 利用 shortrange PCR方法分别对来自黑龙江省和山西省的两个 黄芩个体叶绿体基因组进行测序，组装出叶绿体基因 组大小分别为 $151817 \mathrm{bp}$ 和 $151824 \mathrm{bp}, \mathrm{GC}$ 含量为 
$38.3 \%$ ，共注释出 114 个基因，包括 80 个蛋白质编码基 因、30个tRNA基因和 4 个rRNA基因. 通过与黄芩属 Scutellaria insignis和Scutellaria lateriflora的叶绿体基 因组比较分析, 发现6个可变区(trnH-psbA, trnK-rps 16, pet $N$ - psbM, trnT-trnL, petA-psbJ, ycfl) 可作为黄芩属物 种DNA 条形码鉴定序列，该研究还从GenBank中获取 唇形科 34 个完整的叶绿体基因组序列，以 84 个串联编 码基因为代表构建最大似然系统进化树，从而判断黄 芩在唇形科植物中的系统发育位置, 结果显示, 黄芩 与S. insignis和S. lateriflora亲缘关系最近.

\section{3 黄芩转录组研究}

物种转录组数据可以反映个体在特定器官或组织 的细胞内，以及特定发育或生理阶段的完整基因表达， 可提供所有基因的表达特征并分析不同组织或生理条 件下的基因表达差异，发现与特定生理功能相关的基 因, 并推测未知基因所编码蛋白质的功能. 随着测序 技术的发展，4个黄芩转录组研究相继被报道(测序信 息见表2). Park等人 ${ }^{[29]}$ 以黄芩早期生长的幼苗为样本, 利用罗氏454和Illumina/Solexa HiSeq 2000高通量测 序平台进行测序，首次报道黄芩幼苗的转录组数据, 共组装出 96663 个转录本, 其中 51188 个长度大于 $500 \mathrm{bp}, 31050$ 个长度大于 $1000 \mathrm{bp}$; 基因注释表明，至 少 20498 个转录本在黄芩生长早期表达，126个与植株 生长发育和胁迫应答相关转录因子被挖掘; 基因表达 分析发现， 718 个高表达基因中有 6 个参与植株光合作 用. Liu等人 ${ }^{[30]}$ 利用Solexa/Illumina Hiseq 2000 对黄芩 的根、茎、叶和花 4 个不同组织器官进行测序, 共组装 出 49507 个去冗余后的转录本, 其中 54 个转录本编码黄
酮类成分合成途径中的 12 种关键酶，如CHS、查尔酮 异构酶(chalcone isomerase, CHI)和黄酮醇合成酶(flavonol synthase, FLS)等; 基因差异表达分析发现, 469个 基因在根中显著上调, 推测与活性成分的合成有关. 王 德富等人 ${ }^{[31]}$ 采用Illumina Hiseq 2500 对两年生黄芩的 根、茎、叶和花进行转录组测序和分析, 组装后获得 107533 个转录本和 53353 个去骂余后的转录本, N50分 别为 $1257.69 \mathrm{bp}$ 和797.64 bp. 程林 ${ }^{[33]}$ 基于Illumina 4000 测序平台对干旱胁迫下 (对照、轻度、中度和重度)黄 芩的根进行转录组测序, 研究干旱胁迫对黄芩的影响 机制, 共拼接注释得到57307个去午余的转录本, 发现 转录因子MYB和WRKY可能对干旱胁迫下黄芩苷积 累具有重要调控作用.

前期的黄芩转录组测序均采用二代测序技术, 由 于测序读长短导致转录本组装碎片化、编码基因注释 不完整等问题. 三代测序技术具有读长长的显著优势, 可覆盖整个转录本，能够准确鉴定编码基因的全长转 录本及可变剪接事件(alternative splicing, AS). 联合二 代和三代全长转录组测序在植物界首次应用于唇形科 物种丹参, 受到国际关注和认可 ${ }^{[34]}$. Gao 等人 ${ }^{[32]}$ 基于杂 和测序方式, 将三代PacBio测序平台长读长和二代Illumina测序平台准确度高的优势相结合, 获得了黄芩 根、茎和叶 3 个组织器官的高质量全长转录组数据, 共获得338136条全长非嵌合(full-length nonchimeric, FLNC) 读长和 75785 个非午余的转录本, $97.27 \%$ 的转 录本长度大于 $1000 \mathrm{bp}$, 显示出全长转录组测序的优 势, 基因注释获得11135个长链非编码RNA(long noncoding RNA, IncRNA)和64650个mRNA; 差异表达分 析显示, 根和叶存在4932 个差异表达基因, 根和茎存在

表 2 黄芩 de novo转录组测序数据

Table 2 De novo sequencing of Scutellaria baicalensis transcriptome

\begin{tabular}{|c|c|c|c|c|c|}
\hline 发表年份 & 测序技术 & 植物来源 & 生长年限 & 测序部位 & 数据 \\
\hline $2014^{[29]}$ & $\begin{array}{c}\text { Roche/454 GS_FLX+和Illu- } \\
\text { mina/Solexa HiSeq } 2000\end{array}$ & 无菌苗 & 三个月 & - & $\begin{array}{l}96663 \text { contigs } \\
20498 \text { transcripts }\end{array}$ \\
\hline $2015^{[30]}$ & Illumina/Solexa HiSeq 2000 & $\begin{array}{c}\text { 北京中医药大学 } \\
\text { 自然植株 }\end{array}$ & 三年生 & 根、茎、叶、花 & 49507 unigenes \\
\hline $2016^{[31]}$ & Illumina HiSeq 2500 & $\begin{array}{c}\text { 山西㖓县 } \\
\text { 黄芩种植基地 }\end{array}$ & 两年生 & 根、茎、叶、花 & $\begin{array}{l}107533 \text { transcripts } \\
53353 \text { unigenes }\end{array}$ \\
\hline $2019^{[32]}$ & PacBio和Illumina & 山东青岛栽培品 & 三年生 & 根、茎、叶 & $\begin{array}{c}75785 \text { transcripts } \\
11135 \text { lncRNA } \\
64650 \text { mRNA } \\
44071 \text { AS events }\end{array}$ \\
\hline
\end{tabular}


3703 个差异表达基因，茎和叶存在2911个差异表达基 因. 黄酮类化合物合成相关基因在根中具有高表达, 与活性成分的积累规律一致. 黄芩中存在 44071 个可 变剪接事件, 三种主要可变剪接类型(内含子保留、 $3^{\prime}$ 端可变剪接、5'端可变剪接)占可变剪接事件的 $98.3 \%$. 篮选到黄酮类化合物合成及调控相关转录本 188 个, 其 中PAL、4CL、黄烷酮-3-羟化酶(flavanone-3-hydroxylase, F3H)、黄烷酮-8-差弪化酶(flavanone-8-hydroxylase, F8H)和R2R3-MYB编码基因存在可变剪接事件.

黄芩转录组 de novo组装及注释、全长转录组研 究、不同组织部位基因差异表达分析等为黄芩活性成 分生物合成相关编码基因的篮选和鉴定以及其可变剪 接事件等奠定了基础. 此外, 转录组测序也用于辅助基 因组注释等相关研究. 相较于其他模式植物, 如药用模 式植物丹参等, 目前的黄芩转录组只针对不同组织部 位(根、茎、叶、花等)研究黄酮类成分合成的关键酶 基因的差异表达及候选基因篮选. 通过转录组揭示黄 芩对于生物胁迫或非生物胁迫的应答及次生代谢产物 合成响应机制的研究还未见报道，因此更深入的黄芩 转录组学研究有助于揭示黄芩生长发育、胁迫应答及 活性成分合成的调控机制.

\section{4 基于组学的分子标记开发}

简单序列重复(simple sequence repeats, SSRs), 也 称微卫星，是1 6个核苷酸或2 8个核苷酸的短串联重

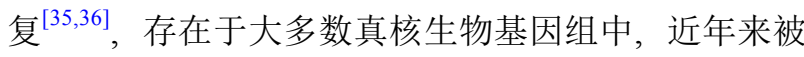
广泛用作分子标记. $\mathrm{Xu}$ 等人 ${ }^{[25]}$ 在黄芩基因组中篮选出 142951条SSRs; 齐琳洁等人 ${ }^{[37]}$ 在黄芩基因组中进行搜 索，共得到12775条SSR序列，最主要的重复基序类型 为二核苷酸 $(68.32 \%)$, 笁选出 9 对 SSR 引物对 10 个不同 产地的 50 个不同植株黄芩基因组DNA进行扩增，结果 表明黄芩具有较高的遗传多样性. Liu等人 ${ }^{[30]}$ 在黄芩转 录组中篎选出6901条SSRs，重复次数5 35次不等，其 中9次最频繁，SSR类型中二核苷酸占所有 SSRs的 $68.5 \%$ ，二聚体重复序列以 $\mathrm{GA} 、 \mathrm{CT} 、 \mathrm{AG}$ 和 $\mathrm{TC}$ 为主， 三聚体重复序列以 TTC 和TCT为主，黄酮类化合物合 成途径中有 7 个转录本具有候选SSRs. 王德富等人 ${ }^{[31]}$ 基于黄芩转录组数据, 利用MISA软件获得了 5658 个 SSR标记位点，二核苷酸占 $51.75 \%$. Yuan等人 ${ }^{[38]}$ 利用 缺水和高温处理影响黄芩素合成, 构建了黄芩根和叶 的全长cDNA文库，获得了6491条表达序列标签(ex- pressed sequence tags, ESTs), 平均读长为 $854 \mathrm{bp}$, 利用 SSRIT工具在 3569 个转录本中检索得到78条EST-SSRs (可用于评价遗传多样性、物种进化和比较基因组学 研究), 其中六核苷酸重复是主要的基序类型 (占 $47.44 \%), 20$ 条SSRs可能与黄芩中黄酮类活性成分的 积累有关. Jiang等人 ${ }^{[28]}$ 在黄芩叶绿体基因组中发现 39 条SSRs, 其中均聚物 25 个、二聚物 4 个、三聚物 3 个、 四聚物 6 个、六聚物 1 个.

得益于测序技术的快速发展，黄芩全基因组及转 录组研究已相对成熟, 高质量的基因组和转录组数据 将全面推进黄芩的科学研究与应用, 为黄芩生长发育 相关功能基因挖掘、活性成分代谢途径解析、合成生 物学及分子辅助育种研究等奠定了基础. SSR分子标 记的开发有助于黄芩不同种质遗传多样性研究，从而 推进黄芩种质资源评价、保存和新品种选育, 解决其 野生资源短缺、人工种植种质退化等问题. 叶绿体及 线粒体基因组测序有助于黄芩的物种鉴定及系统发育 研究, 目前黄芩线粒体基因组仍未被报道, 线粒体基因 组具有丰富的长度多态性以及自身的优势, 在中药分 子鉴定研究上具有一定价值, 值得进行进一步研究, 弥补该方面的空白.

\section{3 黄芩蛋白质组学与代谢组学}

中药蛋白质组学研究包含两方面目标: 一方面是 寻找中药作用于机体时作用靶点的相关蛋白质，从而 阐明其作用机制, 为中药临床应用提供科学依据 ${ }^{[39]}$. 研究人员受黄芩葉具有显著的抗脂肪变性活性启发, 利用定量的化学蛋白质组学研究策略发现, 黄芩苷是 肉毒碱棕榈酰转移酶1(carnitine palmitoyltransferase 1, $\mathrm{CPT} 1$ )的天然变构激活物，可以直接与 CPT1结合并激 活其活性以加速脂肪酸降解，从而显著改善肝脂肪变 性相关症状 ${ }^{[11]}$. 另一方面，通过比较中药不同植株或 同一植株不同组织器官中蛋白质组的差异, 用以评价 中草药活性成分与蛋白组变化的相关性, 进而揭示中 草药活性成分形成的分子机制, 目前基于蛋白质组学 探讨黄芩植物活性成分形成机制的研究甚少，仅Yuan 等人 ${ }^{[40]}$ 基于蛋白质组学研究了缺水胁迫对黄芩中黄 酮类成分含量及组成变化的内在影响机制, 他们在植 株缺水条件下检测到 15 个上调蛋白、3个下调蛋白, 通过分析得出缺水胁迫导致的黄酮类成分变化是激素 
调节的结果. 与基因表达相比,蛋白质表达谱可更准确 地反映参与活性成分生物合成关键酶的表达水平，有 助于揭示在逆境胁迫下药用植物体内次生代谢产物发 生变化的分子机制.

中药代谢组学旨在采用各种分析化学手段, 全局 性定性或定量分析中药小分子代谢产物，从而研究基 因或环境对植物代谢物的影响或揭示药物在机体内 作用的代谢机制 ${ }^{[39]}$. 目前, 代谢组学技术多用于研究 黄芩及其活性成分作用于机体后的代谢变化，药用植 物自身代谢组学报道较少，主要涉及物种鉴别及质量 评价方面. 庞溢媛等 ${ }^{[41]}$ 通过UHPLC-MS/MS(ultrahigh performance liquid chromatography/mass spectrometry)对不同采收时期的黄芩进行化学成分种类和含 量的动态变化检测, 篮选差异代谢物并分析其含量变 化，为探索黄芩最佳采收期提供了理论支持. Kang等 人 $^{[42]}$ 利用核磁共振 (nuclear magnetic resonance, NMR) 结合隐变量正交投影(orthogonal projections to latent structure-discriminant analysis, OPLS-DA)的方法测定 黄芩中的小分子代谢物, 以鉴别中国黄芩与韩国黄芩. Qiao等人 ${ }^{[43]}$ 利用高效液相色谱-混合四极轨道质谱联 用技术，联合创新性的关键离子过滤技术，识别黄芩 甲醇提取物中黄酮类、黄烷酮类、黄酮 $\mathrm{O}-/ \mathrm{C}$-苷类、 苯乙醇苷类成分, 共检测到 132 种成分, 其中 59 个为首 次报道.

中药代谢组学通常结合各种组学技术解析物种活 性成分的生物合成途径、代谢网络及调控机制等. 代 谢组学联合蛋白质组学在中草药中的应用并不罕见, Wang等人 ${ }^{[44]}$ 利用蛋白质组学与代谢组学相结合的方法 研究盐胁迫影响甘草(Glycyrrhiza uralensis)活性成分积 累的作用机制发现，盐胁迫下甘草中黄酮类化合物合 成关键酶(PAL, C4H，4CL CHS, CHI和FLS)及甘草酸 合成关键酶(bAS, CYP88D6和CYP72A154)会显著上调, 且甘草酸等三萜皇苷类成分及多种黄酮类活性成分的 含量在盐胁迫下也会增加，该研究为揭示甘草中黄酮 类和甘草酸代谢的分子机制提供了有价值的蛋白质组 学信息. 类似研究策略还用于揭示大豆(Glycine max)耐 盐机制 ${ }^{[45]}$ 、紫草(Lithospermum erythrorhizon)中紫草素 的合成途径 ${ }^{[46]} 、 M e J A$ 诱导苦蘵(Physalis angulata) 毛状 根中生物活性物质积累的调控机制 ${ }^{[47]}$ 等. 因此, 蛋白质 组学与代谢组学联合用于阐明黄芩体内活性成分的合 成途径及机制, 仍需引起国内外学者的关注.

\section{4 黄芩活性成分生物合成及调控研究}

\section{1 黄芩活性成分生物合成途径解析}

不同骨架的黄酮类化合物在植物中有共同的上 游合成途径 ${ }^{[48]}$ : 植物光合作用积累的碳水化合物首先 经EMP途径(Embden-Meyerhof-Parnas pathway)和PPP 途径(pentose phosphate pathway)形成茾草酸; 莽草酸 转化为苯丙氨酸; 苯丙氨酸经由苯丙氨酸解氨酶、肉 桂酸-4-差化酶(cinnamate-4-hydroxylase, C4H)和4-香 豆酰辅酶 $\mathrm{A}$ 连接酶的依次催化生成对香豆酰辅酶 $\mathrm{A}$; 三分子来源于三羧酸循环的丙二酰辅酶 $\mathrm{A}^{[49]}$ 和一分 子对香豆酰辅酶A在查尔酮合酶的催化下聚合成柚皮 素查尔酮; 或者苯丙氨酸不经过 $\mathrm{C} 4 \mathrm{H}$ 的催化步骤, 生 成4'-脱氧的松属素查尔酮. 查尔酮类化合物进一步由 查尔酮异构酶催化发生立体定向环化反应生成黄烷 酮类骨架——松属素和柚皮素，黄烷酮类可在黄酮合 酶(flavone synthase, FNS)的催化下生成黄酮类, 在二 氢黄酮还原酶(dihydroflavonol 4-reductase, DFR)和花 青素还原酶(anthocyanidin reductase, ANS)的催化下 成生花青素类.

针对黄芩地上与地下部位主要黄酮种类的差异, 黄芩素、汉黄芩素、野黄芩素及其苷类的代谢途径已 被解析(图3). Zhao 等人 ${ }^{[15]}$ 基于转录组测序、基因表 达、进化树等数据分析, 结合毛状根RNA干扰(RNA interference, RNAi)、酵母验证、转基因拟南芥、转 化烟草叶片等功能验证体系, 挖掘并鉴定出参与黄芩 根部 4' -脱氧黄酮类化合物代谢途径的基因依次为: $S b C L L-7, S b C H S-2, S b C H I$ 和SbFNSII-2, 最终催化根中 白杨素的合成; 而参与地上部分芹菜素的合成关键酶 基因为: $S b C L L-1, S b C L L-5, S b C 4 H, S b C H S-1, S b C H I$ 和 SbFNSII-1. 黄芩中编码黄酮-6-美化酶和黄酮-8-羟 化酶( $\mathrm{F} 6 \mathrm{H}$ 和 $\mathrm{F} 8 \mathrm{H}$ )的基因分别被鉴定为 $S b C Y P 82 D 1.1$ 和 SbCYP82D2; 其中, SbCYP82D1.1催化根中白杨素和地 上部位芹菜素分别生成黄芩素和野黄芩素, SbCYP82D2催化根中白杨素生成去甲汉黄芩素和微 量的黄芩素 ${ }^{[0]}$. Zhao 等人 ${ }^{[24]}$ 笁选并克隆 5 个甲基转移 酶基因(PFOMT1 5), 通过功能验证发现 5 个基因均具 有催化去甲汉黄芩素生成汉黄芩素的活性, 其中 PFOMT5的活性最强, PFOMT1和PFOMT2活性次之, PFOMT3和PFOMT4活性极弱. Nagashima等人 ${ }^{[51]}$ 在黄 芩细胞中分离纯化出 7- $O$ - 葡萄糖醛酸转移酶(UDP- 


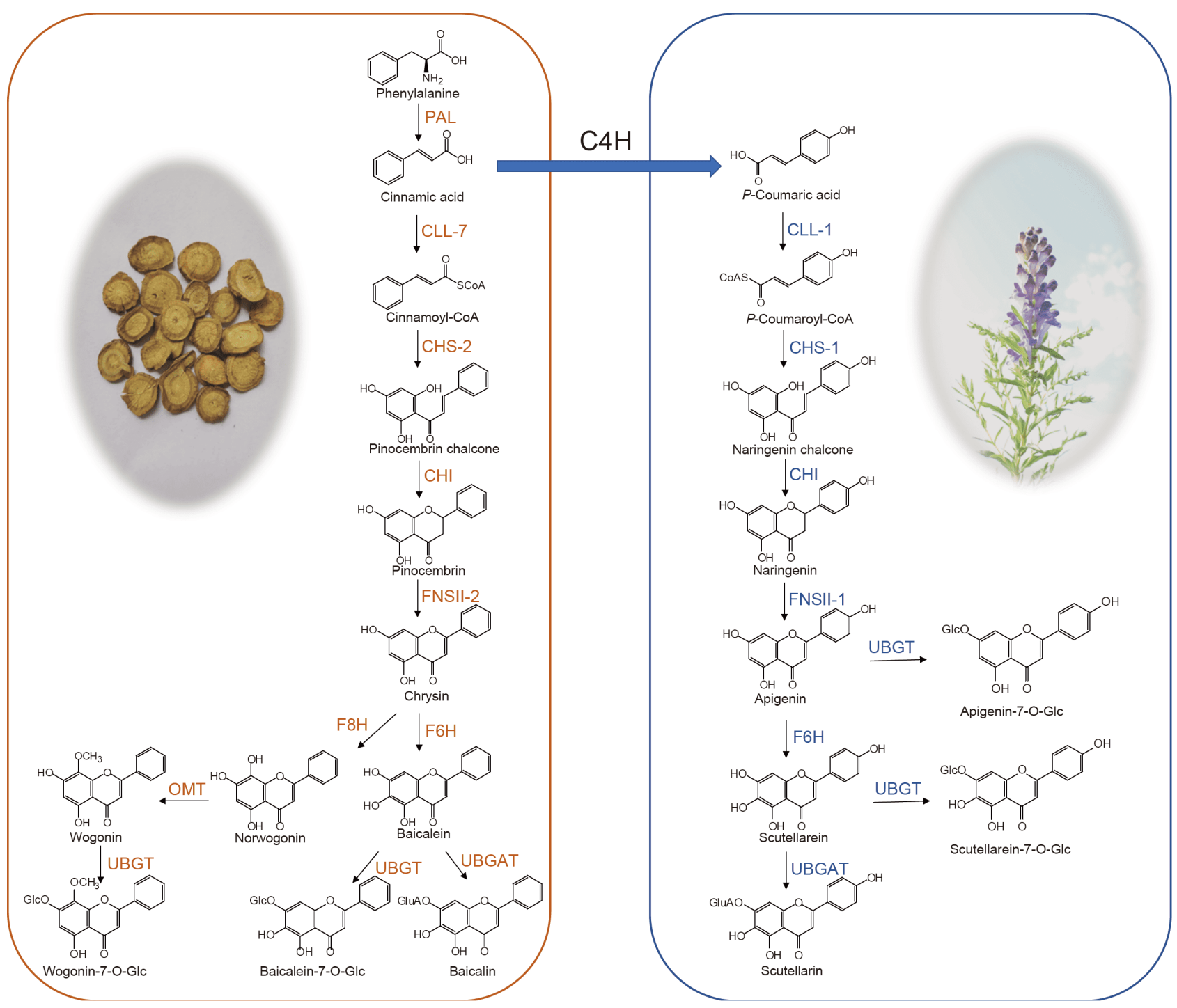

图 3 已解析的黄芩活性成分生物合成途径 ${ }^{[15,24,50 \sim 52]}$ (网络版彩图)

Figure 3 Biosynthetic pathways used to generate active flavonoids in Scutellariabaicalensis ${ }^{[15,24,50 \sim 52]}$ (color online)

glucuronate: baicalein 7-O-glucuronosyltransferase, UBGAT), 该酶可催化黄芩素、汉黄芩素和野黄芩素生成 对应的糖苷类化合物. Hirotani等人 ${ }^{[52]}$ 在黄芩毛状根中 分离出UBGT基因, UBGT可以催化黄芩素、芹菜素、 野黄芩素、汉黄芩素、山奈酚生成对应的7- $O$-葡萄糖 苷类化合物. 2020 年，最新研究 ${ }^{[53]}$ 提出了一种基于空 间分辨的质谱成像技术，实现了黄芩中黄酮类化合物 的定位及其生物合成的可视化，有助于了解其空间合 成代谢网络，该研究通过优化MALDI矩阵，首次绘制 了黄芩素、汉黄芩素、黄芩苷、汉黄芩苷在黄芩根部 的合成途径图谱，发现这些黄酮类化合物及其生物合
成途径相关代谢物在韧皮部的含量显著高于其他部 位, 并且发现4种关键酶(PAL, C4H, 4CL和FNS)在韧皮 部表现出较高活性.

除上述完整合成途径外, Wang等人 ${ }^{[54]}$ 在黄芩中发 现了一种区域特异性糖基转移酶Sb3GT1(UGT78B4), 该酶能在 17 种黄酮醇化合物的 $3-\mathrm{OH}$ 上引入葡萄糖、 半乳糖、 $N$-乙酰葡萄糖胺、木糖和阿拉伯糖，转化率 高达 $98 \%$ ，他们基于分子对接和突变实验预测了导致 糖供体广泛性的关键残基. 另有多篇报道对上游基因 进行了克隆、生物信息分析及功能验证，Zhou等人 ${ }^{[55]}$ 克隆得到 $S b C H S$ 基因，发现黄芩毛状根在受紫外照 
射、创伤及酵母诱导时, 该基因表达降低, 以松属素和 柚皮素为底物, 在大肠杆菌(Escherichia coli)中表达该 蛋白，可显示其显著的查尔酮合成酶活性. $\mathrm{Xu}$ 等人 ${ }^{[56]}$ 克隆出 3 个 $S b P A L$ 和 1 个 $S b C 4 H$ 基因，使用不同浓度茉 莉酸甲酯(methyl jasmonate, MeJa)处理悬浮细胞和诱 导悬浮细胞损伤, $S b P A L, S b C 4 H, S b 4 C L$ 和 $S b C H S$ 基因 的表达水平均上调, 利用HPLC检测发现黄酮化合物的 含量也升高，表明基因与黄芩中黄酮类化合物合成具 有相关性. Park等人 ${ }^{[57]}$ 克隆 $S b C H I$ 基因全长序列, 利用 毛状根体系进行基因过表达和沉默研究，与对照组相 比，SbCHI过表达的毛状根中积累更多的黄酮类化合 物, 而 $S b C H I$ 基因沉默使黄酮含量减少. Kim等人 ${ }^{[58]}$ 对 黄芩中的SbFLS进行克隆和差异表达分析发现, SbFLS 在根和花中表达量较高，其在各组织部位的表达模式 和山奈酚含量分布相似，推测其与山奈酚的生物合成 相关. 迷迭香酸在黄芩花中含量较高，酪氨酸氨基转 移酶(tyrosine aminotransferase，TAT)和羟基苯基丙酮 酸还原酶(hydroxyphenylpyruvate reductase, HPPR)是 其上游合成途径的关键酶, 研究人员克隆和分析了 $S b T A T 1, S b T A T 2$ 和 $S b H P P R$ 基因, 发现它们的表达与迷 迭香酸的积累一致 ${ }^{[59]}$.

综上所述，黄芩根部主要活性成分的合成途径已 经清晰，地上部位除野黄芩苷外，仍有红花苷、异红 花苷等二氢黄酮类化合物的代谢途径未解析，推测由 柚皮素的羟基化产物为中间体，进一步加糖催化生成. 此外, 与其他苷类化合物不同, 黄芩中黄酮苷类活性成 分中的糖基多为葡萄糖醛酸，葡萄糖醛酸转移酶的糖 基特异性分子机制也被揭示. Noguchi等人 ${ }^{[60]}$ 基于对 黄酮7-葡萄糖苷转移酶(flavonoid 7-O-glucuronosyltransferases，F7GAT)的生化、同源建模和系统发育特 征的研究发现，唇形科F7GATs均为UGT88家族成员， 将精氨酸(Arg)替换为色氨酸(Trp)时, 糖供体特异性将 从UDP-葡萄糖醛酸转换为UDP-葡萄糖. 然而合成途 径中其他关键基因的分子机制尚未报道，需进一步 研究.

\section{2 黄芩活性成分生物合成调控研究}

通过转录水平调控发育相关基因及活性成分合 成途径酶基因表达是实现定向、高效调节药用植物 生长及活性成分合成的有效手段之一 ${ }^{[61]}$. Yuan等人 ${ }^{[62]}$ 对黄芩中的R2R3-MYB蛋白进行研究, 从cDNA文库
中共篮选出 19 个 MYB 转录因子, 发现 $S b M Y B 2$ 和 $S b M Y B 7$ 与 $S b P A L$ 具有相近的表达谱, 利用转基因烟草 (Nicotiana tabacum)植株对其进行过表达研究, 证实 SbMYB2或SbMYB7调控黄芩中黄酮类生物合成相关 基因的表达，可上调黄酮类化合物合成的第一步，下 调黄酮类化合物合成的最后一步，且过表达植株中的 二咖啡酰亚精胺(dicaffeoylspermidine)和葪皮素-3,7$O$-二糖苷(quercetin-3,7- $O$-diglucoside)的含量明显降 低. 烟草植株中过表达SbMYB7 基因可使 NtUFGT转录 水平升高, 过表达 $S b M Y B 2$ 基因可使 $N t H C T$ 的转录水 平升高, 但赤需素可以抑制 $S b M Y B 7$ 和 $S b M Y B 2$ 的转录 水平, 说明 SbMYB2和SbMYB7可能通过赤霉素代谢 调节黄酮类化合物的合成, SbMYB8蛋白可与 $S b C H S$ 启动子区 GmMYB92 BS3 序列结合, 调控 $S b C H S$ 的表 达, 从而调控类黄酮生物合成, 且过表达 $S b M Y B 8$ 可提 高转基因烟草的抗逆性, 并可改变某些抗氧化酶的活 性和基因表达水平，结果表明SbMYB8在植物类黄酮 的合成和抗逆性方面起着重要的作用 ${ }^{[63]}$. 陈媞颖等 人 $^{[64,65]}$ 在黄芩转录组和 $\mathrm{cDNA}$ 文库中分别篎选出 9 个 $A R F$ 基因和 6 个 $b H L H$ 基因, 并对其进行了生物信息学 研究和赤霉素刺激下的差异表达分析：其中 $A R F$ 基因 在黄芩的花中表达较高, $b H L H$ 基因在黄芩的根和花 中表达较高，二者均与黄芩中黄酮类化合物的合成及 调控基因的表达具有一定的相关性.

转录因子在植物次生代谢、生长发育及胁迫响应 中有着至关重要的作用. 丹参中 SmERF128能正向调 控丹参酮合成关键酶基因的表达，在SmERF128过表 达的毛状根中丹参酮含量显著增加，在 $S m E R F 128$ RNAi毛状根中丹参酮含量降低 ${ }^{[66]}$. 扁桃(Prunus dul$c i s)$ 中 b H L H 2 调控苦杏仁苷生物合成途径中 $P d C Y P 79 D 16$ 和PdCYP71AN24的转录，对其进行非同 义点突变(亮氨酸突变为苯丙氨酸)可阻止两个基因的 转录, 从而导致甜核仁性状 ${ }^{[67]}$. 转录因子家族主要包 括bZIP, MYB, WRKY, AP2/ERF和NAC等, 基于全基 因组的药用模式物种丹参 AP2 $/ \mathrm{ERF}^{[68]}, \mathrm{bZIP}{ }^{[69]}$ 和 $\mathrm{bHLH}^{[70]}$ 转录因子家族已被报道, 系统进化、保守基 序、结合位点及可变剪接事件也被揭示. 目前, 有关 黄芩中转录因子调控的研究不够全面与深入，黄芩基 因组已解析，基于基因组篮选与生长发育、胁迫响应 及活性成分生物合成相关的转录因子并进行功能机制 研究是今后研究方向之一. 


\section{5 黄芩活性成分合成生物学研究}

随着组学技术和基因工程的快速发展，合成生物 学进入快速发展阶段, 利用合成生物学合成药物活性 成分，是解决中药资源短缺以及化学合成环境污染的 有效途径, 合成生物学的优势已在青蒿酸(青蒿素前

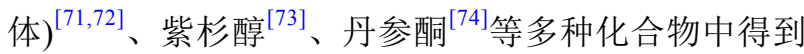
了有效验证. 类黄酮类化合物作为一大类植物次生代 谢产物, 同样受到研究人员的关注.

松属素、柚皮素及芹菜素为黄芩苷及野黄芩苷合 成的中间产物，且是多种黄酮类化合物的重要前体物 质, 研究较充分. Lee等人 ${ }^{[75]}$ 利用大肠杆菌为底盘细胞 合成芹菜素和芫花素, 培养 $30 \mathrm{~h}$ 后, 在不转化为芫花素 的情况下，芹菜素产量可积累到 $100 \mathrm{mg} / \mathrm{L}$, Thuan等 人 ${ }^{[76]}$ 以大肠杆菌为底盘细胞构建共培养系统: 香豆酸 生产芹菜素系统和芹菜素生产芹黄素葡萄糖苷(apigetrin)系统，得到芹菜素和芹黄素葡萄糖苷产量分别为 $31.8 \mu \mathrm{mol} / \mathrm{L}$ 和 $38.5 \mu \mathrm{mol} / \mathrm{L} . \mathrm{Wu}$ 等人 ${ }^{[77]}$ 利用大肠杆菌 为底盘细胞, 在 $3 \mathrm{~L}$ 发酵罐中生产 $2 \mathrm{~S}$-松属素, 其产量达 到 $432.4 \mathrm{mg} / \mathrm{L}$. 目前以葡萄糖为原料合成柚皮素的产 量可达 $144.1 \mathrm{mg} / \mathrm{L}^{[78]}$, 以酪氨酸为原料, 柚皮素产量可 达 $252.4 \mathrm{mg} / \mathrm{L}^{[79]}$, 以香豆酸 $p$-coumaric acid)为原料, 柚 皮素的产量可达到 $648.63 \mathrm{mg} / \mathrm{L}^{[80]}$. Palmer等人 ${ }^{[81]}$ 利用 产油酵母Yarrowia lipolytica为底盘细胞，从头合成柚 皮素的产量可达 $898 \mathrm{mg} / \mathrm{L}$. 此外，体外无细胞合成系 统也开始应用在柚皮素的生产中, 以香豆酸为底物培 养3 h后, 柚皮素产量为 $11.22 \mathrm{mg} / \mathrm{L}^{[82]}$.

黄芩素和野黄芩素的合成生物学研究已取得初步 进展. $\mathrm{Li}$ 等人 ${ }^{[83]}$ 以大肠杆菌为底盘细胞, 利用来自于7 个不同物种的黄酮生物合成途径基因构建工程菌, 分 别以苯丙氨酸和酪氨酸为底物生产黄芩素和野黄芩 素. 首先利用圆红冬狍酵母(Rhodotorula toruloides)的 苯丙氨酸解氨酶、欧芹(Petroselinum crispum)中的4香豆酰辅酶A连接酶、碧冬茄(Petunia hybrida)中的查 尔酮合酶、紫花苜宿(Medicago sativa) 中的查尔酮异 构酶、欧芹的黄酮合成酶(FNSI), 当饲喂 $0.5 \mathrm{~g} / \mathrm{L}$ 的 L苯丙氨酸和酪氨酸时, 白杨素和芹菜素的产量可达到 $28.8 \mathrm{mg} / \mathrm{L}$ 和 $109.7 \mathrm{mg} / \mathrm{L}$. 随后，为了改善P450在大肠 杆菌中的表达和溶解，将亲水性的 $2 \mathrm{~B} 1$ 与 $\mathrm{N}$-端截短 22 个氨基酸的 $\mathrm{SbF} 6 \mathrm{H}$ 结合，使用拟南芥的全长 $\mathrm{CPR}(\mathrm{Ara}-$ bidopsis cytochrome P450 reductase, AtCPR), 并通过
优化大肠杆菌中的丙二酰辅酶 $\mathrm{A}$, 最终以苯丙氨酸为 底物饲喂培养 $48 \mathrm{~h}$ 后黄芩素产量为 $23.6 \mathrm{mg} / \mathrm{L}$, 以酪氨 酸为底物饲喂得到野黄芩素产量为 $106.5 \mathrm{mg} / \mathrm{L}$. 黄芩 地上部分主要活性成分——野黄芩苷, 也是药用植物 短葶飞蓬(Erigeron breviscapus)中的主要活性成分, 研 究人员验证了短葶飞蓬野黄芩苷合成途径中的 $\mathrm{F} 6 \mathrm{H}$ 和 UGT的基因功能，利用 $E b F 6 H$ 和 $E b 7 G A T$ 在酿酒酵母 (Saccharomyces cerevisiae W303-1B)底盘中构建灯戞 花素合成的细胞工厂，通过代谢工程改造与发酵工艺 优化, 以芹菜素为底物培养7天, 最终野黄芩苷(灯盏花 素的主要成分)产量为 $108 \mathrm{mg} / \mathrm{L}^{[84]}$.

目前, 黄芩主要活性成分的合成生物学研究较少 且产量较低, 提高合成生物学产量的方法有: ( i ) 改 变底盘细胞种类. 已有黄芩活性成分的合成生物学研 究以酿酒酵母或大肠杆菌为底盘细胞, 可尝试具有丰 富膜结构和亚细胞间隔的产油酵母，它们能为类黄酮 的区域选择性和立体选择性提供理想的疏水环境. (ii) 挖掘篮选高效基因. 糖基转移酶和甲基转移酶的 挖掘与鉴定, 为汉黄芩素和黄酮苷物质的合成提供了 有效的基因元件. Mark等人 ${ }^{[85]}$ 从基因篮选的角度，比 较不同物种中的 4 CL 和CHS基因转入酿酒酵母中合成 柚皮素的产率发现，静僽苜宿的4CL和葡萄的CHS组 合可使柚皮素的产量最高; 基因突变也可改变基因的 转化效率, 研究人员通过对 CHS进行突变, 增大了生 成肉桂酸的转变率. (iii) 优化合成途径和合成工艺. Lyu等人 ${ }^{[86]}$ 通过加入吐温-80改善溶解性等方式，提高 产物上清中的产量; $\mathrm{Wu}$ 等人 ${ }^{[87]}$ 以柚皮素的生产为模 型, 利用CRISPR(clustered regularly interspaced short palindromic repeats)系统来提高其产量.

\section{6 总结与展望}

黄芩作为我国传统中药材已有数千年的药用历 史, 是中成药及复方的重要组成, 目前研究认为黄芩的 主要活性成分为类黄酮类化合物，主要包括黄芩素、 野黄芩素、汉黄芩素以及它们的糖苷类化合物等, 其 中野黄芩苷(又名灯戞乙素)在临床上用于心脑血管疾 病的治疗，临床使用的灯戞乙素制品来自于菊科植物 短葶飞蓬, 黄芩植物的地上部分野黄芩苷含量也较高, 且黄芩植株较大, 资源相对较丰富, 有望成为野黄芩苷 的重要植物来源. 
2019年, 《中共中央 国务院关于促进中医药传承 创新发展的意见》中提出, 中药材质量良莠不齐, 要大 力推动中药质量提升和产业高质量发展. 测序技术和 生物技术的快速发展在中医药学与现代生命科学之间 架起一座桥梁，越来越多的药用植物生物学本质被揭 示. 黄芩是一种大宗常用药材, 面临野生资源骤减、人 工栽培种源混乱、种质退化、市售药材质量不一等问 题, 组学的快速发展为提升黄芩药材质量提供了重要 支撑, 也为黄芩药物开发指明方向. 为推动黄芩可持续 发展和科学应用, 我们认为今后研究人员可从以下 6 个 方面开展工作：（i ）活性成分生物合成及生长发育调 控机制研究，前文总结黄芩中主要活性成分代谢途径 和关键基因功能验证已取得突破性进展，但仍有活性 成分生物合成的功能基因未被鉴定，且黄芩活性成分 合成与生长发育调控及抗逆性相关研究较为薄弱. (ii) 提高黄芩活性成分合成生物学产量, 与化学提取和化 学合成相比, 合成生物学具有环境友好等优势, 黄芩活 性成分合成生物学研究已取得初步成效, 但工程菌合 成的效率及产量较低, 合成生物学元件及发酵体系等
需要进一步优化, 提升合成生物学产量, 进而实现产业 化生产, 实现黄芩可持续发展. (iii) 道地药材形成机制 研究, 从分子水平揭示道地产区黄芩的物种遗传变异 和基因型, 明确环境因素对道地药材基因表达的影响, 从而科学保护黄芩道地产区环境, 或者模拟道地产区 环境, 进行黄芩规范化种植. (iv) 优良新品种选育, 基 于黄芩全基因组及分子标记技术，通过对不同种质资 源进行重测序, 篮选优良性状相关基因, 开发优良新品 种并进行种质保存与推广. ( v ) 黄芩市场流通质量监 管, 王彦峰等人 ${ }^{[88]}$ 对全球1980 2018年间有关黄芩的专 利进行数据分析发现, 其研发正处于快速发展阶段, 黄 芩中药材、中成药、保健功能的食品和茶饮是当前研 究热点, 市场流通监管成为极大挑战, 研究人员提出可 将中药材DNA条形码转换为二维码应用于市场流通监 管体系 ${ }^{[89]}$, 该数字化手段将推动建立中药材质量追溯 体系及市场规范化. (vi) 运用多组学方法揭示黄芩活 性成分功能机制, 黄芩及其活性成分具有良好的临床 应用前景, 通过多组学的联合应用, 挖掘黄芩活性成分 的新机制与新靶点, 助力新药研发.

\section{参考文献}

1 Chinese Pharmacopoeia Commission. Pharmacopoeia of the People's Republic of China, Vol I (in Chinese). Beijing: China Medical Science Press, 2015. 301-302 [国家药典委员会. 中华人民共和国药典(一部). 北京: 中国医药科技出版社, 2015. 301-302]

2 Bian Y Q, Ma J, Ren Y, et al. Discovery of intervention effect of Chinese herbal formulas on COVID-19 pulmonary fibrosis treated by VEGFR and FGFR inhibitors (in Chinese). China J Chin Mater Med, 2020, 45: 1481-1487 [边亚倩, 马婧, 任越, 等. 基于VEGFR, FGFR探讨中药方剂 对COVID-19后遗症肺纤维化的干预作用. 中国中药杂志, 2020, 45: 1481-1487]

3 Liu H B, Ye F, Sun Q, et al. Scutellaria baicalensis extract and baicalein inhibit replication of SARS-CoV-2 and its 3C-like protease in vitro. bioRxiv, 2020

4 Li J H, Ling F F, Du J Y, et al. Antiviral effects of baicalin combined with peramivir against pandemic 2009 H1N1 virus in vitro and in vivo (in Chinese). Chin Pharmacol Bull, 2013, 29: 617-621 [李健猴, 凌芳芳, 杜金燕, 等. 黄芩苷联合帕拉米韦体内外抗甲型H1N1流感病毒作用. 中 国药理学通报, 2013, 29: 617-621]

5 Chen F, Chan K H, Jiang Y, et al. In vitro susceptibility of 10 clinical isolates of SARS coronavirus to selected antiviral compounds. J Clin Virol, 2004, 31: 69-75

6 Zhi H J, Zhu H Y, Zhang Y Y, et al. In vivo effect of quantified flavonoids-enriched extract of Scutellaria baicalensis root on acute lung injury induced by influenza A virus. Phytomedicine, 2019, 57: 105-116

7 Ji S, Li R, Wang Q, et al. Anti-H1N1 virus, cytotoxic and Nrf2 activation activities of chemical constituents from Scutellaria baicalensis. J Ethnopharmacol, 2015, 176: 475-484

$8 \mathrm{Zu} \mathrm{M}$, Zhou D, Gao L, et al. Evaluation of Chinese traditional patent medicines against influenza virus in vitro (in Chinese). Acta Pharm Sin, 2010, 45: 408-412 [祖勉, 周丹, 高丽, 等. 临床常用中成药的体外抗流感病毒活性评价. 药学学报, 2010, 45: 408-412]

9 Chen Y, Hui H, Yang H, et al. Wogonoside induces cell cycle arrest and differentiation by affecting expression and subcellular localization of PLSCR1 in AML cells. Blood, 2013, 121: 3682-3691

10 Tsou L K, Lara-Tejero M, RoseFigura J, et al. Antibacterial flavonoids from medicinal plants covalently inactivate type III protein secretion 
substrates. J Am Chem Soc, 2016, 138: 2209-2218

11 Dai J, Liang K, Zhao S, et al. Chemoproteomics reveals baicalin activates hepatic CPT1 to ameliorate diet-induced obesity and hepatic steatosis. Proc Natl Acad Sci USA, 2018, 115: E5896-E5905

12 Zeng A, Liang X, Zhu S, et al. Baicalin, a potent inhibitor of NF- $\kappa \mathrm{B}$ signaling pathway, enhances chemosensitivity of breast cancer cells to docetaxel and inhibits tumor growth and metastasis both in vitro and in vivo. Front Pharmacol, 2020, 11: 879

13 Liu J, Zhang T, Wang Y, et al. Baicalin ameliorates neuropathology in repeated cerebral ischemia-reperfusion injury model mice by remodeling the gut microbiota. Aging, 2020, 12: 3791-3806

14 Zhu L, Xu L Z, Zhao S, et al. Protective effect of baicalin on the regulation of Treg/Th17 balance, gut microbiota and short-chain fatty acids in rats with ulcerative colitis. Appl Microbiol Biotechnol, 2020, 104: 5449-5460

15 Zhao Q, Zhang Y, Wang G, et al. A specialized flavone biosynthetic pathway has evolved in the medicinal plant, Scutellaria baicalensis. Sci Adv, 2016, 2: e1501780

16 Wang Z L, Wang S, Kuang Y, et al. A comprehensive review on phytochemistry, pharmacology, and flavonoid biosynthesis of Scutellaria baicalensis. Pharm Biol, 2018, 56: 465-484

17 Zhao T, Tang H, Xie L, et al. Scutellaria baicalensis Georgi. (Lamiaceae): a review of its traditional uses, botany, phytochemistry, pharmacology and toxicology. J Pharm Pharmacol, 2019, 71: 1353-1369

18 Zhao Q, Chen X Y, Martin C. Scutellaria baicalensis, the golden herb from the garden of Chinese medicinal plants. Sci Bull, 2016, 61: 13911398

19 Shen J. Study on quality assessment of the aerial parts of Scutellaria baicalensis Georgi and a primary pharmacophylogenetic investigation in the genus Scutellaria (in Chinese). Dissertation for Master's Degree. Beijing: Peking Union Medical College, 2018 [申洁. 黄芩地上部位质量评价 研究及黄芩属药用亲缘学初探. 硕士学位论文. 北京: 北京协和医学院, 2018]

20 Deshmukh A B, Datir S S, Bhonde Y, et al. De novo root transcriptome of a medicinally important rare tree Oroxylum indicum for characterization of the flavonoid biosynthesis pathway. Phytochemistry, 2018, 156: 201-213

21 He C N, Peng Y, Xiao W, et al. Application history and research status quo of Huang-qin tea (in Chinese). Mod Chin Med, 2011, 13: 3-7+19 [何 春年, 彭勇, 肖伟, 等. 黄芩茶的应用历史与研究现状. 中国现代中药, 2011, 13: 3-7+19]

22 He C N, Peng Y, Xiao W, et al. Comparative study chemical composition in aerial parts and roots of Scutellaria baicalensis (in Chinese). Mod Chin Med, 2011, 13: 32-35 [何春年, 彭勇, 肖伟, 等. 黄芩地上部分与根部的化学成分比较研究. 中国现代中药, 2011, 13: 32-35]

23 Cole I B, Cao J, Alan A R, et al. Comparisons of Scutellaria baicalensis, Scutellaria lateriflora and Scutellaria racemosa: genome size, antioxidant potential and phytochemistry. Planta Med, 2008, 74: 474-481

24 Zhao Q, Yang J, Cui M Y, et al. The reference genome sequence of Scutellaria baicalensis provides insights into the evolution of wogonin biosynthesis. Mol Plant, 2019, 12: 935-950

$25 \mathrm{Xu} \mathrm{Z} \mathrm{C,} \mathrm{Gao} \mathrm{R} \mathrm{R,} \mathrm{Pu} \mathrm{X} \mathrm{D,} \mathrm{et} \mathrm{al.} \mathrm{Comparative} \mathrm{genome} \mathrm{analysis} \mathrm{of} \mathrm{Scutellaria} \mathrm{baicalensis} \mathrm{and} \mathrm{Scutellaria} \mathrm{barbata} \mathrm{reveals} \mathrm{the} \mathrm{evolution} \mathrm{of} \mathrm{active}$ flavonoid biosynthesis. bioRxiv, 2020

26 Wicke S, Schneeweiss G M, dePamphilis C W, et al. The evolution of the plastid chromosome in land plants: gene content, gene order, gene function. Plant Mol Biol, 2011, 76: 273-297

$27 \mathrm{Xu} \mathrm{Z}$, Xin T, Bartels D, et al. Genome analysis of the ancient tracheophyte Selaginella tamariscina reveals evolutionary features relevant to the acquisition of desiccation tolerance. Mol Plant, 2018, 11: 983-994

28 Jiang D, Zhao Z, Zhang T, et al. The chloroplast genome sequence of Scutellaria baicalensis provides insight into intraspecific and interspecific chloroplast genome diversity in Scutellaria. Genes, 2017, 8: 227

29 Park N I, Choi I Y, Choi B S, et al. EST sequencing and gene expression profiling in Scutellaria baicalensis. EXCLI J, 2014, 13: 392-400

30 Liu J, Hou J, Jiang C, et al. Deep sequencing of the Scutellaria baicalensis Georgi transcriptome reveals flavonoid biosynthetic profiling and organ-specific gene expression. PLoS ONE, 2015, 10: e0136397

31 Wang D F, Cheng Y Y, Yang F, et al. Transcriptome data assembly and analysis of Scutellaria baicalensis through high-throughput sequencing (in Chinese). J Shanxi Agric Sci, 2016, 44: 1065-1072 [王德富, 成媛媛, 杨锋, 等. 黄芩高通量转录组测序数据组装和分析. 山西农业科学, 44: 1065-1072]

32 Gao T, Xu Z, Song X, et al. Hybrid sequencing of full-Length cDNA transcripts of the medicinal plant Scutellaria baicalensis. Int J Mol Sci, 2019, 20: 4426 
33 Cheng L. Physiological and ecological changes of Scutellaria baicalensis Georgi under drought stress and molecular ecological mechanism of baicalin biosynthesis (in Chinese). Dissertation for Doctoral Degree. Changchun: Jilin Agricultural University, 2018 [程林. 干旱胁迫黄芩生理 生态变化及其黄芩苷生物合成的分子生态机制. 博士学位论文. 长春: 吉林农业大学, 2018]

$34 \mathrm{Xu}$ Z, Peters R J, Weirather J, et al. Full-length transcriptome sequences and splice variants obtained by a combination of sequencing platforms applied to different root tissues of Salvia miltiorrhiza and tanshinone biosynthesis. Plant J, 2015, 82: 951-961

35 van Belkum A, Scherer S, van Alphen L, et al. Short-sequence DNA repeats in prokaryotic genomes. Microbiol Mol Biol Rev, 1998, 62: 275-293

36 Gur-Arie R, Cohen C J, Eitan Y, et al. Simple sequence repeats in Escherichia coli: abundance, distribution, composition, and polymorphism. Genome Res, 2000, 10: 62-71

37 Qi L J, Long P, Jiang C, et al. Development of microsatellites and genetic diversity analysis of Scutellaria baicalensis Georgi using genomic-SSR markers (in Chinese). Acta Pharm Sin, 2015, 50: 500-505 [齐琳洁, 龙平, 蒋超, 等. 黄芩基因组SSR分子标记的开发及遗传多样性分析. 药学 学报, 2015, 50: 500-505]

38 Yuan Y, Long P, Jiang C, et al. Development and characterization of simple sequence repeat (SSR) markers based on a full-length cDNA library of Scutellaria baicalensis. Genomics, 2015, 105: 61-67

39 Xin T, Zhang Y, Pu X, et al. Trends in herbgenomics. Sci China Life Sci, 2019, 62: 288-308

40 Yuan Y, Liu Y, Wu C, et al. Water deficit affected flavonoid accumulation by regulating hormone metabolism in Scutellaria baicalensis Georgi roots. PLoS ONE, 2012, 7: e42946

41 Pang Y Y, Xue L Y, Zheng Y H, et al. Comparative study on quality of Scutellaria baicalensis Georgi in different harvest periods using UHPLCMS/MS metabolomics technology (in Chinese). Acta Pharm Sin, 2017, 52: 1903-1909 [庞溢媛, 薛立英, 郑艳红, 等. 基于UHPLC-MS/MS代谢 组学技术的不同采收期黄芩质量比较研究. 药学学报, 2017, 52: 1903-1909]

42 Kang J, Choi M Y, Kang S, et al. Application of a ${ }^{1} \mathrm{H}$ nuclear magnetic resonance (NMR) metabolomics approach combined with orthogonal projections to latent structure-discriminant analysis as an efficient tool for discriminating between Korean and Chinese herbal medicines. J Agric Food Chem, 2008, 56: 11589-11595

43 Qiao X, Li R, Song W, et al. A targeted strategy to analyze untargeted mass spectral data: Rapid chemical profiling of Scutellaria baicalensis using ultra-high performance liquid chromatography coupled with hybrid quadrupole orbitrap mass spectrometry and key ion filtering. $\mathrm{J}$ Chromatogr A, 2016, 1441: 83-95

44 Wang C, Chen L, Cai Z C, et al. Comparative proteomic analysis reveals the molecular mechanisms underlying the accumulation difference of bioactive constituents in Glycyrrhiza uralensis fisch under salt stress. J Agric Food Chem, 2020, 68: 1480-1493

45 Pi E, Zhu C, Fan W, et al. Quantitative phosphoproteomic and metabolomic analyses reveal GmMYB173 optimizes flavonoid metabolism in soybean under salt stress. Mol Cell Proteomics, 2018, 17: 1209-1224

46 Takanashi K, Nakagawa Y, Aburaya S, et al. Comparative proteomic analysis of Lithospermum erythrorhizon reveals regulation of a variety of metabolic enzymes leading to comprehensive understanding of the shikonin biosynthetic pathway. Plant Cell Physiol, 2019, 60: 19-28

47 Zhan X, Liao X, Luo X, et al. Comparative metabolomic and proteomic analyses reveal the regulation mechanism underlying MeJA-induced bioactive compound accumulation in cutleaf groundcherry (Physalis angulata L.) hairy roots. J Agric Food Chem, 2018, 66: 6336-6347

48 Yonekura-Sakakibara K, Higashi Y, Nakabayashi R. The origin and evolution of plant flavonoid metabolism. Front Plant Sci, 2019, 10: 943

49 Koes R E, Quattrocchio F, Mol J N M. The flavonoid biosynthetic pathway in plants: Function and evolution. Bioessays, 1994, 16: 123-132

50 Zhao Q, Cui M Y, Levsh O, et al. Two CYP82D enzymes function as flavone hydroxylases in the biosynthesis of root-specific 4'-deoxyflavones in Scutellaria baicalensis. Mol Plant, 2018, 11: 135-148

51 Nagashima S, Hirotani M, Yoshikawa T. Purification and characterization of UDP-glucuronate: baicalein 7-O-glucuronosyltransferase from Scutellaria baicalensis Georgi. cell suspension cultures. Phytochemistry, 2000, 53: 533-538

52 Hirotani M, Kuroda R, Suzuki H, et al. Cloning and expression of UDP-glucose: flavonoid 7-O-glucosyltransferase from hairy root cultures of Scutellaria baicalensis. Planta, 2000, 210: 1006-1013

53 Sun C, Zhang M, Dong H, et al. A spatially-resolved approach to visualize the distribution and biosynthesis of flavones in Scutellaria baicalensis Georgi. J Pharm Biomed Anal, 2020, 179: 113014

54 Wang Z, Wang S, Xu Z, et al. Highly promiscuous flavonoid 3-O-glycosyltransferase from Scutellaria baicalensis. Org Lett, 2019, 21: 22412245

55 Zhou Y, Nagashima S, Hirotani M, et al. Expression of the chalcone synthase gene in Scutellaria baicalensis hairy root cultures was unusually 
reduced by environmental stresses. Plant Biotech, 2003, 20: 207-214

$56 \mathrm{Xu} \mathrm{H}$, Park N I, Li X, et al. Molecular cloning and characterization of phenylalanine ammonia-lyase, cinnamate 4-hydroxylase and genes involved in flavone biosynthesis in Scutellaria baicalensis. Bioresour Tech, 2010, 101: 9715-9722

57 Park N I, Xu H, Li X, et al. Enhancement of flavone levels through overexpression of chalcone isomerase in hairy root cultures of Scutellaria baicalensis. Funct Integr Genomics, 2011, 11: 491-496

58 Kim Y B, Kim K S, Kim Y J, et al. Cloning and characterization of a flavonol synthase gene from Scutellaria baicalensis. Sci World J, 2014, 2014: $1-7$

$59 \operatorname{Kim}$ Y B, Uddin M R, Kim Y J, et al. Molecular cloning and characterization of tyrosine aminotransferase and hydroxyphenylpyruvate reductase, and rosmarinic acid accumulation in Scutellaria baicalensis. Nat Product Commun, 2014, 9: 1934578X1400900

60 Noguchi A, Horikawa M, Fukui Y, et al. Local differentiation of sugar donor specificity of flavonoid glycosyltransferase in Lamiales. Plant Cell, 2009, 21: 1556-1572

61 Ji A J, Luo H M, Xu Z C, et al. Research and perspectives on AP2/ERF transcription factors in medicinal plants (in Chinese). Chin Sci Bull, 2015, 60: 1272-1284 [季爱加, 罗红梅, 徐志超, 等. 药用植物转录因子AP2/ERF研究与展望. 科学通报, 2015, 60: 1272-1284]

62 Yuan Y, Wu C, Liu Y, et al. The Scutellaria baicalensis R2R3-MYB transcription factors modulates flavonoid biosynthesis by regulating GA metabolism in transgenic tobacco plants. PLoS ONE, 2013, 8: e77275

63 Yuan Y, Qi L, Yang J, et al. A Scutellaria baicalensis R2R3-MYB gene, SbMYB8, regulates flavonoid biosynthesis and improves drought stress tolerance in transgenic tobacco. Plant Cell Tiss Organ Cult, 2014, 120: 961-972

64 Chen T Y, Liu J, Yuan Y, et al. Bioinformatics analysis and expressed level of auxin response factor genes in Scutellaria baicalensis (in Chinese). Acta Pharm Sin, 2017, 52: 1770-1776 [陈媞颖, 刘娟, 袁媛, 等. 黄芩ARF基因家族生物信息学及表达分析. 药学学报, 2017, 52: 1770-1776]

65 Chen T Y, Liu J, Yuan Y, et al. Analysis of bioinformatics and expression level of bHLH transcription factors in Scutellaria baicalensis (in Chinese). Chin Tradit Herb Drugs, 2018, 49: 671-677 [陈媞颖 刘娟, 袁媛, 等. 黄芩bHLH转录因子基因家族生物信息学及表达分析. 中草 药, 2018, 49: 671-677]

66 Zhang Y, Ji A, Xu Z, et al. The AP2/ERF transcription factor SmERF128 positively regulates diterpenoid biosynthesis in Salvia miltiorrhiza. Plant Mol Biol, 2019, 100: 83-93

67 Sánchez-Pérez R, Pavan S, Mazzeo R, et al. Mutation of a bHLH transcription factor allowed almond domestication. Science, 2019, 364: 10951098

68 Ji A J, Luo H M, Xu Z C, et al. Genome-wide identification of the AP2/ERF gene family involved in active constituent biosynthesis in Salvia miltiorrhiza. Plant Genome, 2016, 9: plantgenome2015.08.0077

69 Zhang Y, Xu Z, Ji A, et al. Genomic survey of bZIP transcription factor genes related to tanshinone biosynthesis in Salvia miltiorrhiza. Acta Pharm Sin B, 2018, 8: 295-305

70 Zhang X, Luo H, Xu Z, et al. Genome-wide characterisation and analysis of bHLH transcription factors related to tanshinone biosynthesis in Salvia miltiorrhiza. Sci Rep, 2015, 5: 11244

71 Westfall P J, Pitera D J, Lenihan J R, et al. Production of amorphadiene in yeast, and its conversion to dihydroartemisinic acid, precursor to the antimalarial agent artemisinin. Proc Natl Acad Sci USA, 2012, 109: E111-E118

72 Ro D K, Paradise E M, Ouellet M, et al. Production of the antimalarial drug precursor artemisinic acid in engineered yeast. Nature, 2006, 440: 940-943

73 Ajikumar P K, Xiao W H, Tyo K E J, et al. Isoprenoid pathway optimization for taxol precursor overproduction in Escherichia coli. Science, 2010, 330: 70-74

74 Guo J, Zhou Y J, Hillwig M L, et al. CYP76AH1 catalyzes turnover of miltiradiene in tanshinones biosynthesis and enables heterologous production of ferruginol in yeasts. Proc Natl Acad Sci USA, 2013, 110: 12108-12113

75 Lee H, Kim B G, Kim M, et al. Biosynthesis of two flavones, apigenin and genkwanin, in Escherichia coli. J Microbiol Biotech, 2015, 25: 14421448

76 Thuan N H, Chaudhary A K, Van Cuong D, et al. Engineering co-culture system for production of apigetrin in Escherichia coli. J Ind Microbiol Biotechnol, 2018, 45: 175-185

$77 \mathrm{Wu}$ J, Zhang X, Dong M, et al. Stepwise modular pathway engineering of Escherichia coli for efficient one-step production of (2S)-pinocembrin. J Biotech, 2016, 231: 183-192 
78 Du Y, Yang B, Yi Z, et al. Engineering Saccharomyces cerevisiae coculture platform for the production of flavonoids. J Agric Food Chem, 2020, 68: $2146-2154$

79 Lv Y, Marsafari M, Koffas M, et al. Optimizing oleaginous yeast cell factories for flavonoids and hydroxylated flavonoids biosynthesis. ACS Synth Biol, 2019, 8: 2514-2523

80 Gao S, Lyu Y, Zeng W, et al. Efficient biosynthesis of (2S)-naringenin from p-coumaric acid in Saccharomyces cerevisiae. J Agric Food Chem, 2020, 68: 1015-1021

81 Palmer C M, Miller K K, Nguyen A, et al. Engineering 4-coumaroyl-CoA derived polyketide production in Yarrowia lipolytica through a $\beta$ oxidation mediated strategy. Metab Eng, 2020, 57: 174-181

82 Zang Y, Zha J, Wu X, et al. In vitro naringenin biosynthesis from p-coumaric acid using recombinant enzymes. J Agric Food Chem, 2019, 67: 13430-13436

83 Li J, Tian C, Xia Y, et al. Production of plant-specific flavones baicalein and scutellarein in an engineered E. coli from available phenylalanine and tyrosine. Metab Eng, 2019, 52: 124-133

84 Liu X, Cheng J, Zhang G, et al. Engineering yeast for the production of breviscapine by genomic analysis and synthetic biology approaches. Nat Commun, 2018, 9: 448

85 Mark R, Lyu X, Ng K R, et al. Gene source screening as a tool for naringenin production in engineered Saccharomyces cerevisiae. ACS Omega, 2019, 4: 12872-12879

86 Lyu X, Zhao G, Ng K R, et al. Metabolic engineering of Saccharomyces cerevisiae for de novo production of kaempferol. J Agric Food Chem, 2019, 67: 5596-5606

$87 \mathrm{Wu} \mathrm{J}$, Du G, Chen J, et al. Enhancing flavonoid production by systematically tuning the central metabolic pathways based on a CRISPR interference system in Escherichia coli. Sci Rep, 2015, 5: 13477

88 Wang Y F, Yi T M, Liu H B. Patent pattern analysis of Scutellariae radix (in Chinese). Chin Tradit Herb Drugs, 2019, 50: 5117-5124 [王彦峰, 崀 铁梅, 刘海波. 黄芩专利格局分析. 中草药, 2019, 50: 5117-5124]

89 Xin T Y, Li X W, Yao H, et al. A two-dimensional DNA barcode system for circulation regulation of traditional Chinese medicine (in Chinese). Sci Sin Vitae, 2015, 45: 695-702 [辛天怡, 李西文, 姚辉, 等. 中药材二维DNA条形码流通监管体系研究. 中国科学: 生命科学, 2015, 45: 695-702] 


\title{
Research progress in biosynthesis and synthetic biology of active ingredients of Scutellaria baicalensis Georgi based on multi-omics approach
}

\author{
GAO RanRan ${ }^{1}$, XU ZhiChao ${ }^{1,2}$, PU XiangDong ${ }^{1}$ \& SONG JingYuan ${ }^{1,2,3}$ \\ 1 Key Lab of Chinese Medicine Resources Conservation, State Administration of Traditional Chinese Medicine of the People's Republic of China, \\ Institute of Medicinal Plant Development, Chinese Academy of Medical Sciences \& Peking Union Medical College, Beijing 100193, China; \\ 2 Engineering Research Center of Chinese Medicine Resource, Ministry of Education, Beijing 100193, China; \\ 3 Yunnan Branch, Institute of Medicinal Plant Development, Chinese Academy of Medical Sciences \& Peking Union Medical College, \\ Jinghong 666100, China
}

Scutellaria baicalensis Georgi is a common kind of traditional Chinese medicine; it promotes heat-clearing and detoxification and has been used to treat coronavirus disease 2019. Scutellaria baicalensis contains a unique group of flavonoids that are largely distributed within the Scutellaria species. As such, there is significant interest in research focused on the metabolic pathways that promote endogenous flavonoid production and methods that might be used for their in vitro biosynthesis. However, as is the case with various Chinese medicinal herbs, there are still many challenges to overcome including shortage of wild resources, degradation associated with the cultivated germplasm, and instability leading to uneven product quality. The use of a multiomics approach will provide genetic information as well as insights into the endogenous mechanisms of flavonoid biosynthesis and their regulation, thus promoting frontier research and practical application of traditional Chinese medicine. In this study, we presented a systematic review of genomics, transcriptomics, proteomics, and metabolomics associated with S. baicalensis; our current understanding of the functional genes that promote biosynthesis in vivo as well as the methods that facilitate the in vitro biosynthesis of active compounds are summarized. We also discussed the critical factors associated with further development of S. baicalensis including the cultivation of enriched varieties through genome-assisted breeding, regulatory mechanisms associated with plant growth and development, and optimization of conditions that promote biosynthesis of active compounds both in vivo and in vitro. This review provides a foundation for determining effective solutions for issues associated with the cultivation of $S$. baicalensis and for the production of high quality products.

Scutellaria baicalensis, flavonoids, biosynthesis, synthetic biology

doi: $10.1360 / \mathrm{SSV}-2020-0185$ 